\title{
Impactos de desastres socioambientais em saúde pública: estudos dos casos dos Estados de Santa Catarina em 2008 e Pernambuco em 2010
}

\author{
Luciana de Resende Londe* \\ Victor Marchezini ${ }^{\star \star}$ \\ Rodrigo Silva da Conceição** \\ Katia Cristina Bortoletto ${ }^{* \star \star \star}$ \\ Ana Elisa Pereira Silva* \\ Elisa Volker dos Santos \\ Regina Tortorella Reani
}

\begin{abstract}
Eventos como inundações e movimentos de massa podem provocar desastres, afetando amplamente a saúde pública brasileira. Além de mortes, traumas e lesões, podem ocorrer danificação de estações de tratamento de água, postos de saúde e hospitais, comprometimento de equipamentos e estoque de remédios, epidemias e proliferação de doenças, bem como danos psicossociais. Neste artigo, com o objetivo de identificar e analisar características pré e pós-impacto relacionadas à saúde pública, são estudados dois cenários: inundações ocorridas em Santa Catarina, em 2008, e em Pernambuco, em 2010. Procuramos analisar as condições socioambientais e de cobertura de serviços de saúde prévias e os danos pós-impacto em municípios que decretaram estado de calamidade pública. Para caracterizar a vulnerabilidade socioambiental, foram utilizados dados do Instituto Brasileiro de Geografia e Estatística (IBGE) do Serviço Geológico do Brasil (CPRM), da Secretaria Nacional de Proteção e Defesa Civil (Sedec) e do Sistema Único de Saúde (Datasus). Encontramos grandes diferenças entre os dois estados, principalmente nos indicadores sociais, mas os efeitos das inundações foram severos para ambos, incluindo maior número de óbitos em Santa Catarina, estado com alto índice de desenvolvimento humano e menores índices de pobreza. Estes resultados evidenciam a necessidade de inclusão do tema saúde pública em todas as etapas do gerenciamento do risco de desastres.
\end{abstract}

Palavras-chave: Vulnerabilidade. Eventos extremos. Brasil.

\footnotetext{
* Centro Nacional de Monitoramento e Alertas de Desastres Naturais (Cemaden), São José dos Campos-SP, Brasil (luciana. londe@cemaden.gov.br).

${ }^{\star \star}$ Centro Nacional de Monitoramento e Alertas de Desastres Naturais (Cemaden), São José dos Campos-SP, Brasil (victor. marchezini@cemaden.gov.br).

${ }^{* \star \star}$ Centro Nacional de Monitoramento e Alertas de Desastres Naturais (Cemaden), São José dos Campos-SP, Brasil (rodrigo. conceicao@cemaden.gov.br).

${ }^{\star \star \star \star}$ Centro Nacional de Monitoramento e Alertas de Desastres Naturais (Cemaden), São José dos Campos-SP, Brasil (katia. bortoletto@cemaden.gov.br).

${ }_{\star \star \star \star \star \star}$ Centro Nacional de Monitoramento e Alertas de Desastres Naturais (Cemaden), São José dos Campos-SP, Brasil (ana. silva@cemaden.gov.br).

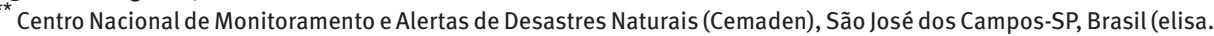
santos@cemaden.gov.br).

Centro Nacional de Monitoramento e Alertas de Desastres Naturais (Cemaden), São José dos Campos-SP, Brasil (reginareani.cemaden@gmail.com).
} 


\section{Introdução}

Nos anos recentes, a intensificação da vulnerabilidade socioambiental, associada à ocorrência de eventos extremos de secas e tempestades, tem ocasionado um estado de crise crônica no Brasil (VALENCIO, 2012). De 2003 a 2014 foram emitidas 22.098 portarias de Situação de Emergência e/ou Estado de Calamidade Pública, em virtude de estiagens, secas, inundações, enxurradas, alagamentos e deslizamentos. Destaca-se que, no conjunto destas estatísticas, não têm sido incorporados os desastres humanos de natureza biológica associados às epidemias, como as de dengue e leptospirose. Os impactos na saúde pública, em geral, são subvalorizados e classificados como "desastres secundários" (BRASIL, 2007a; 2007b).

Os efeitos dos desastres na saúde pública estão relacionados aos danos materiais da estrutura de atendimento do setor e aos danos humanos sofridos pela população. Os fenômenos naturais podem afetar a operação dos sistemas de saúde de forma direta, provocando danificação nas instalações, interrupção de serviços básicos, destruição de vias de comunicação e um número inesperado de mortes e enfermidades, excedendo a capacidade de atenção da rede de serviços (OPAS, 2003). Os prejuízos associados à estrutura de atendimento referem-se, também, ao comprometimento de equipamentos e estoque de remédios (PEREIRA et al., 2014). Já os danos sofridos pela população podem ser classificados de acordo com o período de ocorrência. Danos em curto prazo, por exemplo, incluem períodos que variam entre horas e dias, cujos registros, de acordo com Freitas et al. (2014), abrangem principalmente mortalidade e feridos leves e graves. Em médio prazo há o aumento de doenças, especialmente aquelas de veiculação hídrica e também as transmitidas por vetores, como dengue e malária. Impactos em longo prazo incluem processos depressivos e danos psicossociais, vivenciados, em sua maioria, pelo abandono social no processo de reconstrução e recuperação (VALENCIO; SIENA; MARCHEZINI, 2011; ISDR, 2011; FREITAS et al., 2014).

De forma indireta, os impactos incluem deslocamento da população em busca de atendimento, aumento do risco de transmissão de doenças contagiosas e transtornos psicológicos, desnutrição decorrente do desabastecimento de alimentos, redução e/ou encarecimento dos serviços de saúde, diminuição e/ou contaminação do abastecimento de água potável e modificação das prioridades de saúde, com suspensão de campanhas para atenção a emergências (OPAS, 2003).

Considerando que os impactos dos desastres à saúde ultrapassam os limites de lesões e traumas em curto prazo, o objetivo deste artigo é identificar e analisar impactos de desastres em saúde pública, especificamente os prejuízos materiais da estrutura de atendimento do setor de saúde e os danos humanos sofridos pela população, tomando-se como referência as inundações em Santa Catarina (2008) e Pernambuco (2010). A avaliação destes impactos pode subsidiar as políticas públicas de planejamento para gestão de riscos de desastres, tanto em ações de emissão de alertas com identificação dos impactos 
potenciais de determinado cenário de risco, como nas ações de resposta e recuperação por parte do Sistema Nacional de Proteção e Defesa Civil.

\section{Fundamentação teórica}

Cutter, Boruff e Shirley (2003) identificam três princípios nas pesquisas envolvendo vulnerabilidade: a identificação de condições que tornam pessoas ou lugares vulneráveis a eventos extremos; a interpretação de vulnerabilidade como uma condição social; e a integração de exposições potenciais e resiliência social com foco em regiões específicas. Os autores observam que as vulnerabilidades criadas socialmente são ignoradas, principalmente, devido à dificuldade em quantificá-las, ressaltando a ausência de análises de perdas sociais em relatórios com estimativas de prejuízos de desastres. A vulnerabilidade social seria o produto de desigualdades sociais e também incluiria desigualdades de lugar: características do ambiente construído; nível de urbanização; e taxas de crescimento (CUTTER; BORUFF; SHIRLEY, 2003).

Para Marandola Jr. e Hogan (2005), os dois principais horizontes de vulnerabilidade dividem-se entre pobreza e desigualdade, de um lado, e sua dimensão ambiental nas várias escalas, de outro.

Alves e Torres (2006), considerando a disparidade entre perspectiva sociológica (atrelada à noção de vulnerabilidade social, focada na análise de indivíduos, famílias ou grupos sociais) e a perspectiva da geografia física (associada à noção de vulnerabilidade ambiental, compreendendo o território como regiões e ecossistemas), propõem a construção da noção de vulnerabilidade socioambiental como integradora das dimensões social e ambiental. Ao realizarem uma pesquisa no município de São Paulo, os autores inferem que há, em alguns espaços da periferia, uma coexistência dos piores indicadores socioeconômicos com riscos de alagamentos, inundações, deslizamentos de terra, ambientes intensamente poluídos e serviços sociais ineficientes (ALVES, 2006; ALVES; TORRES, 2006). Assim, nessa espécie de periferia da periferia, existem "situações de extrema pauperização e péssimas condições sociais e exposição cumulativa a diversos tipos de risco" (ALVES; TORRES, 2006, p. 46).

Essa exposição cumulativa a riscos sociais e ambientais não decorre de fenômenos naturais, mas sim de processos sociais, históricos e territoriais, cujas práticas econômicas e político-institucionais tornam vulneráveis determinados grupos sociais (ACSELRAD, 2006). Antes da estação chuvosa já estão definidos quem serão os expostos aos riscos socioambientais, a que tipos de riscos estarão suscetíveis e quais os graus de exposição. Os mecanismos de produção social do risco e de sua exposição desproporcional dentro das redes técnico-produtivas da riqueza se manifestam sob a forma de proteção ambiental desigual e também pelo acesso desigual aos recursos ambientais (LAVELL, 1993; ACSELRAD, 2010; ACSERALD et al., 2008).

Diante desse processo de vulnerabilização, têm sido produzidas estratégias de gestão corretiva do risco. Para Barcellos et al. (1998), a identificação de grupos populacionais 
submetidos a riscos constitui uma etapa indispensável para elaboração de programas de saúde preventivos e avaliação de exposições diferenciadas.

A caracterização da população com relação aos impactos em saúde envolve muitas variáveis. Watson, Gayer e Connolly (2007) propõem uma avaliação sistemática do risco de doenças transmissíveis para responder às necessidades da população afetada por um desastre, identificando:

- doenças endêmicas e epidêmicas comuns na área afetada pelo desastre;

- condições de moradia da população afetada, incluindo número de moradias, tamanho, localização e densidade;

- disponibilidade de água potável e saneamento;

- estado nutricional e cobertura de imunização (vacinas) da população;

- grau de acesso a serviços de saúde e gerenciamento efetivo de casos.

Barcellos et al. (1988) propõem a identificação de áreas e populações submetidas a riscos para a saúde, considerando os seguintes fatores: dificuldade na obtenção de água pela ausência de rede de distribuição nas proximidades dos domicílios; contaminação recorrente da água por bactérias do grupo coliforme; e captação de água em mananciais locais sem tratamento ou sujeitos à contaminação eventual. De modo geral, caracterizar e compreender as diferentes vulnerabilidades socioambientais que se expressam no território é fundamental para avaliar os impactos potenciais dos desastres na saúde pública.

\section{Método}

Considerando os vários referenciais para caracterização de vulnerabilidade socioambiental atrelada a questões de saúde pública, selecionamos dois estados com características distintas para explorar estes referenciais e identificar suas relações com as questões de saúde pública.

Foram utilizados como base de análise dados dos municípios que decretaram estado de calamidade pública ${ }^{1}$ em razão de inundações nos estados de Santa Catarina (novembro de 2008) e Pernambuco (junho de 2010).

Para caracterizar a vulnerabilidade socioambiental, analisamos alguns indicadores propostos por Watson, Gayer e Connolly (2007) e dados do Instituto Brasileiro de Geografia e Estatística (IBGE), junto à sua base de informações sobre municípios brasileiros (IBGE Cidades), da Companhia de Pesquisa de Recursos Minerais (CPRM),2 a partir do mapeamento e fichas de descrição das áreas de risco, da Secretaria Nacional de Proteção e Defesa Civil

\footnotetext{
${ }^{1}$ Estado de calamidade pública é o “reconhecimento (legal) pelo poder público de situação anormal, provocada por desastres, causando sérios danos à comunidade afetada, inclusive à incolumidade ou à vida de seus integrantes” (BRASIL, 2007a, p. 8).

${ }^{2}$ Apenas os municípios de São Benedito do Sul (PE) e Rio dos Cedros (SC), entre os analisados, não tiveram suas áreas de risco mapeadas pela CPRM.
} 
(Sedec), por meio dos Formulários de Avaliação de Danos (Avadan),3 e do Departamento de Informática do Sistema Único de Saúde (Datasus).

\section{Caracterização dos cenários de vulnerabilidade e risco de desastres}

A noção geral de vulnerabilidade a desastres é definida como uma situação em que estão presentes três componentes: exposição ao risco; incapacidade de reação; e dificuldade de adaptação diante da concretização do risco (CUTTER, 1996; MARANDOLA JR.; HOGAN, 2005; ALVES; TORRES, 2006).

Os cenários analisados neste artigo - Pernambuco em 2010 e Santa Catarina em 2008 -, mostrados nas Figuras 1 e 2, foram selecionados para análise por apresentarem diferentes condições referentes às componentes supracitadas. Ao se analisar a coexistência dos piores indicadores socioeconômicos com riscos de inundações, alagamentos e de deslizamentos (ALVES; TORRES, 2006), notam-se diferentes contextos entre os municípios analisados para os dois estados.

Em Pernambuco, este cenário caracteriza-se pela ocupação urbana em áreas suscetíveis, legalmente protegidas como de preservação permanente, a exemplo das planícies de inundação. Em vários municípios do estado observam-se aterros e construções às margens dos rios em porções urbanas, reduzindo a calha e favorecendo seu estrangulamento. A retirada da mata ciliar e a pavimentação reduzem ainda mais a área de drenagem para 0 solo. 0 perímetro de inundação em Barreiros, por exemplo, situa-se quase totalmente na zona central da cidade (correspondendo a quase um terço da área urbana) (CPRM, 2012).

Sobre a ocupação humana, em geral, percebem-se condições sociais desfavoráveis nestes municípios pernambucanos, principalmente no que se refere à capacidade de suporte à população diante dos prejuízos materiais e à saúde, como o baixo/médio nível de desenvolvimento humano (IDHM entre 0,530 e 0,640, em 2010) e porcentagem de pobres entre 38,40\% e 60,86\% em 2010 (IBGE, 2015; PNUD; IPEA; FJP, 2013).

Parte do município de Água Preta situa-se na planície de inundação do Rio Una - principal de sua bacia - e, segundo o Serviço Geológico do Brasil (CPRM), muitas moradias estão sujeitas à inundação em períodos de grande precipitação. Em Barra de Guabiraba, o cenário de risco é agravado pelo lançamento de grande quantidade de águas servidas sem tratamento nos rios e riachos (CPRM, 2012).

\footnotetext{
${ }^{3}$ O Avadan é o documento utilizado pela Sedec e disponibilizado pelo Sistema Integrado de Informações sobre Desastres (S2ID). A partir de 2012, ele foi substituído pelo Formulário de Informações do Desastre (Fide). Para o presente estudo, os Avadan de Rodeio (SC) e Barra de Guabiraba (PE) não foram analisados por não estarem disponíveis.
} 
FIGURA 1

Municípios que declararam estado de calamidade pública, total de estabelecimentos públicos de saúde que foram afetados ou destruídos e pessoas atingidas pelas inundações

Estado de Pernambuco - 2010

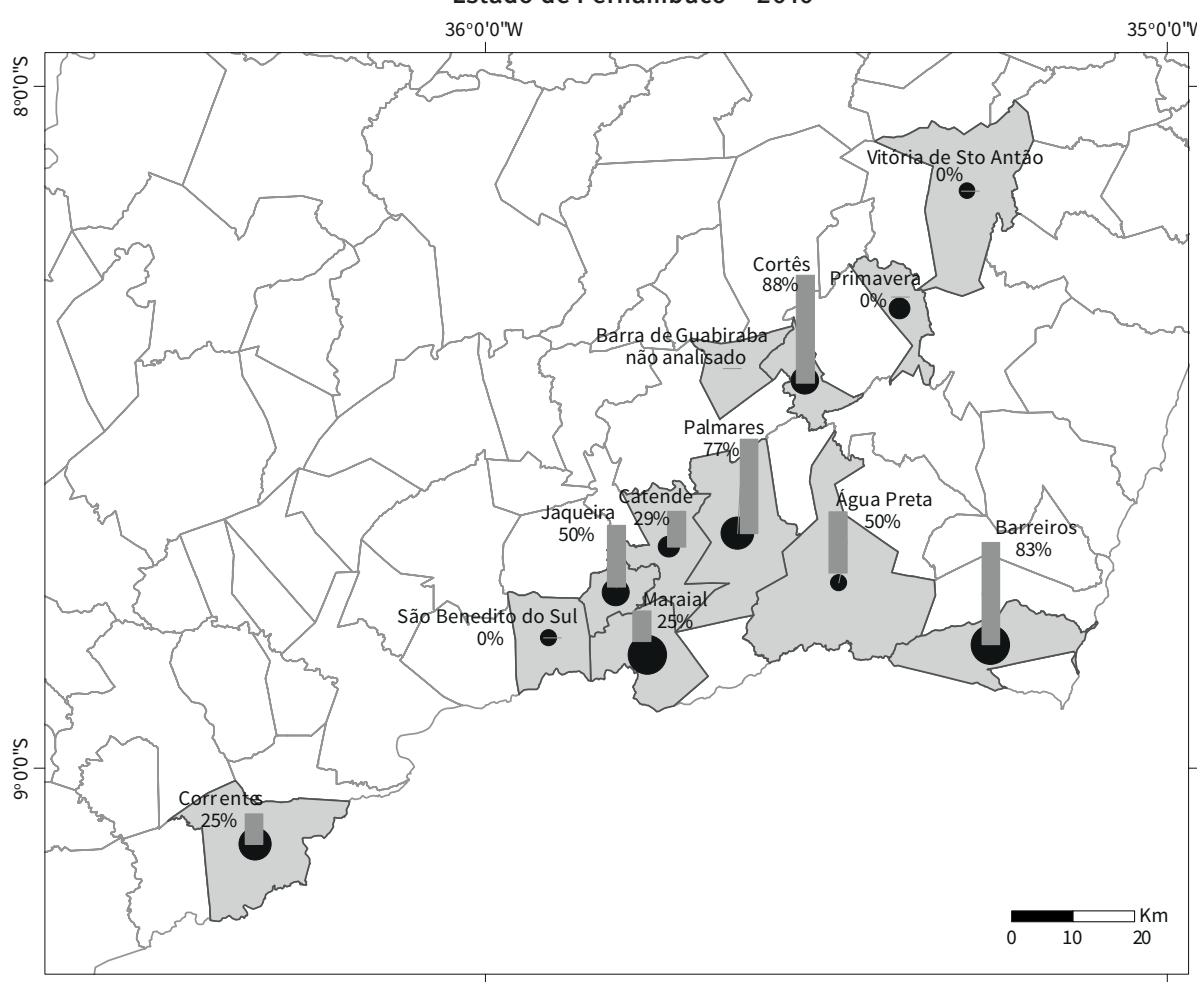

Legenda

Total de afetados (\%) Total de estabelecimentos públicos de saúde danificados/destruídos: 44

- 3 - 39

$40-45$

46-65

- $66-99$

(100-102

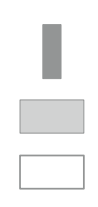

Estabelecimentos públicos de saúde danificados/destruídos (\%)

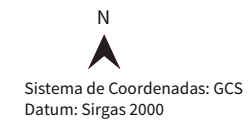

Municípios que decretaram estado de calamidade pública (ECP)

Municípios do Estado de Pernambuco

Fonte: IBGE (2010); Secretaria Nacional de Defesa Civil (2015).

Ainda na bacia do Rio Una, no município de Barreiros (com um total de 40.732 habitantes), a situação de exposição ao risco é ainda mais latente ao se considerar que cerca de $90 \%$ de sua população reside em áreas suscetíveis à inundação, inclusive dentro da calha dos rios, segundo informações da CPRM (2012).

De acordo com dados do IBGE (2015), entre os municípios analisados, Vitória de Santo Antão possui o maior número de residentes e a maior densidade demográfica $(348,8$ habitantes por $\mathrm{km}^{2}$ ). Parte de sua zona urbana é atravessada pelo Rio Tapacurá e seu afluente, com intensa ocupação da planície de inundação e da calha do rio por construções irregulares (CPRM, 2012). 
A exposição ao risco ocorre também em zonas rurais. No município de Cortês, por exemplo, identificam-se aglomerados rurais sobre a planície de inundação do Rio Sirinhaém. Nestas áreas foram registrados processos hidrológicos de alta energia em períodos de chuvas, compreendendo uma situação de risco, agravada pela vulnerabilidade de algumas moradias (CPRM, 2012). Ressalta-se ainda que, embora o número de domicílios e de pessoas seja menor na zona rural destes municípios, em comparação às suas zonas urbanas, a densidade domiciliar média é superior na zona rural (com exceção do município de Correntes, onde a densidade domiciliar média é maior na zona urbana) (IBGE, 2015). Assim, ainda que os danos materiais possam ser menores em áreas rurais, os impactos sobre a população exposta ao risco podem ser consideráveis.

Ilustrando a situação, destaca-se o município de São Benedito do Sul, com as maiores médias de densidade domiciliar em áreas rurais (4,84 habitantes por domicílio) e total (4,43 habitantes por domicílio). Este município caracteriza-se ainda por possuir o maior percentual de população (36\%) atendida com saneamento ambiental inadequado (IBGE, 2015), dentro deste grupo. Isso implica um maior número de pessoas, em relação à população total, expostas a doenças de veiculação hídrica, por exemplo. Deve-se considerar ainda que os surtos de doenças podem ser deflagrados no período pós-inundação.

Além dos impactos humanos potenciais, observa-se ainda a exposição aos danos materiais. Em Catende, por exemplo, devido à grande captação de água pelos Rios Panelas e Pirangi (tributários do Rio Una), os eventos extremos de precipitação e as inundações são acompanhados de enxurradas de alta energia com grande poder destrutivo para as construções e pontes (CPRM, 2012). Esta situação é latente também nos municípios de Jaqueira e Maraial, com áreas de risco associadas ao Rio Pirangi, e no município de Primavera, com áreas de risco relacionadas ao Rio Ipojuca (CPRM, 2012).

É fato que as características fisiográficas da bacia hidrográfica determinam a intensidade e a velocidade do processo. Por exemplo, embora o Rio Mundaú, que corta o município de Correntes, não seja classificado como um rio de grande porte, sua vazão pode atingir um valor muito maior em relação ao seu volume normal devido à configuração do terreno, com elevações acima de 700 metros (CPRM, 2012).

Em comparação com os municípios pernambucanos, o grupo de municípios catarinenses (Figura 2) possui, no geral, condições socioeconômicas que podem ser mais favoráveis ao enfrentamento da situação de desastre. A maioria deles tem alto nível de desenvolvimento humano (IDHM entre 0,726 e 0,795 e Blumenau com 0,806, considerado um nível de desenvolvimento muito alto, em 2010). Entre os municípios catarinenses analisados, a incidência de pobreza, em 2003, chama a atenção apenas em Camboriú $(36,93 \%)$ e Itapoá (41,03\%) (IBGE, 2015). 
FIGURA 2

Municípios que declararam estado de calamidade pública, total de estabelecimentos públicos de saúde que foram afetados ou destruídos e pessoas atingidas pelas inundações

Estado de Santa Catarina - 2008

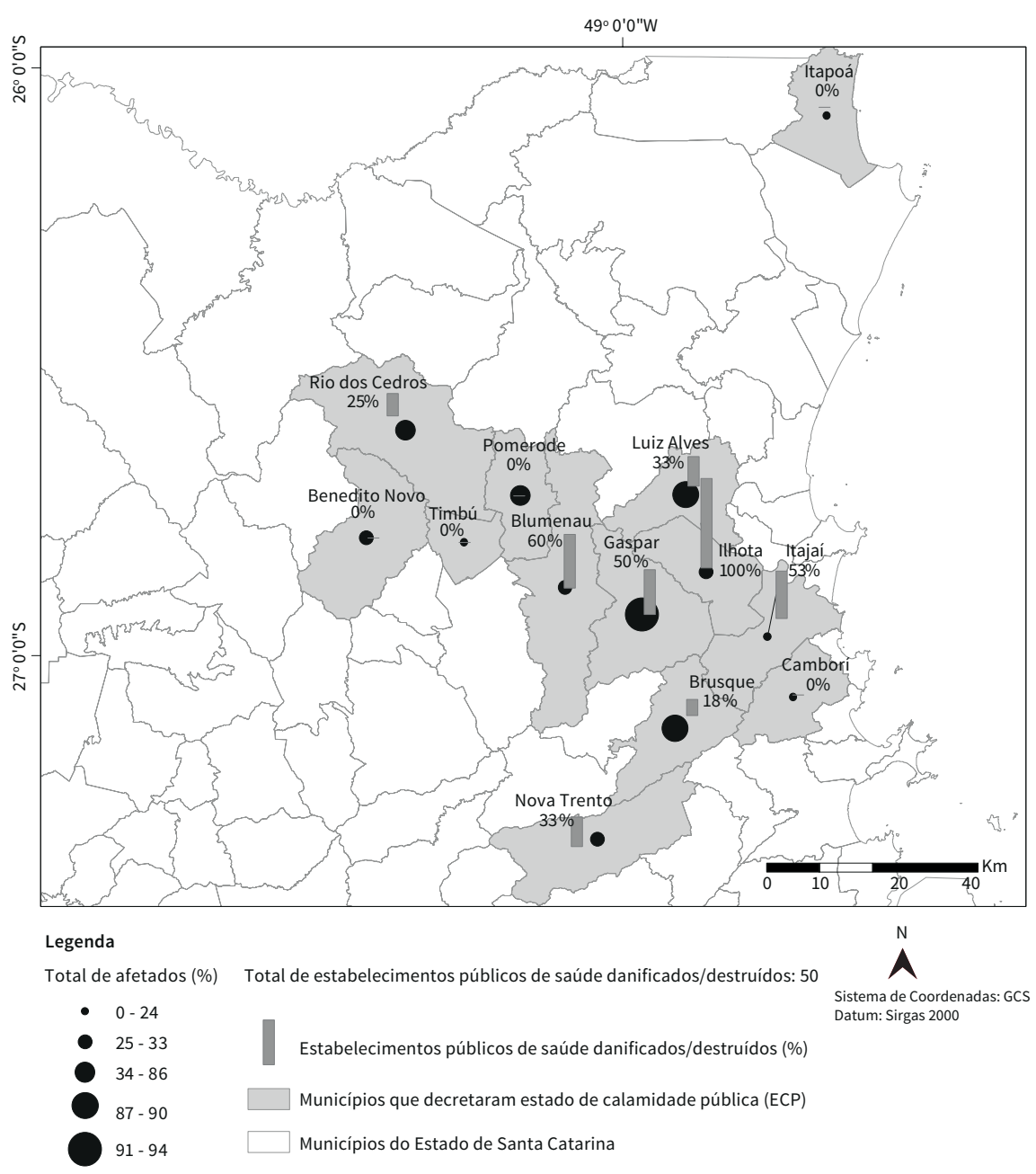

Fonte: IBGE (2010); Secretaria Nacional de Defesa Civil (2015).

Por outro lado, apesar de melhores indicadores socioeconômicos, as características de ocupação dos municípios catarinenses analisados colocam grande parte da população em situação de risco. 0 relevo acidentado da porção leste do estado, com vales encaixados e encostas íngremes, condicionou a ocupação humana nas planícies fluviais - áreas naturalmente sujeitas a inundações - e encostas, áreas sujeitas a movimentos de massa. Somam-se a isso os processos de industrialização e desenvolvimento econômico que atraíram fluxos migratórios e induziram ocupações e intervenções no ambiente - como desmatamentos, cortes, aterros e construções precárias (SANTOS, 2012). 
Em Benedito Novo, ocorrem ocupações sobre planícies fluviais, sujeitas a inundações e enxurradas, e em encostas íngremes, expostas a movimentos de massa. Nesse cenário, identificam-se moradias com alta vulnerabilidade, problemas de drenagem pluvial e ausência de esgotamento sanitário (CPRM, 2013). Ressalta-se que o município possui a maior parte de seus domicílios (65,8\%) com saneamento ambiental semiadequado (IBGE, 2015). Já em Gaspar destacam-se as ocupações ribeirinhas, com construções precárias, expostas ao risco de inundação e solapamento de margem (CPRM, 2013). No entanto, este município caracteriza-se por possuir a maior parte de seus domicílios $(76,8 \%)$ com saneamento ambiental adequado (IBGE, 2015).

Diante deste quadro heterogêneo, destaca-se que alguns municípios possuem elevado número de habitantes e uma ocupação densificada. Blumenau registrava, em 2010, uma densidade demográfica de aproximadamente 595 habitantes por km², com população majoritariamente urbana (IBGE, 2015). Nesse sentido, é importante considerar o elevado grau de urbanização nas margens dos cursos d'água, a intensa artificialização do solo e, consequentemente, a existência de problemas relacionados à drenagem e inundações bruscas nas áreas urbanas, afetando um grande contingente populacional (CPRM, 2013). Situação parecida pode ser verificada nos municípios de Brusque e Itajaí, que concentram, juntamente com Blumenau, o maior número de afetados no evento de 2008.

A partir da análise desses dados, pode-se inferir que existem diferentes contextos de vulnerabilidade socioambiental, caracterizados por grandes contrastes. Esta desigualdade pré-impacto pode contribuir para a produção social do desastre.

$\mathrm{Na}$ análise da vulnerabilidade direcionada às questões de saúde pública, uma das variáveis propostas por Watson, Gayer e Connolly (2007) é a situação de epidemias e endemias. Nas áreas que foram afetadas em Pernambuco e Santa Catarina, há registros de hepatites virais, meningite, leptospirose e dengue em período anterior ao desastre, porém, com exceção da dengue, os números (BRASIL, 2015a) não caracterizam epidemias ou endemias.

Outras dimensões importantes referem-se às condições de moradia da população afetada e saneamento. Os dados da Tabela 1 apontam para uma grande diferença entre os municípios dos dois estados.

O número de pessoas residentes em domicílios particulares com saneamento inadequado ${ }^{4}$ variou entre 2.236 e 11.539 por município, em Pernambuco, e entre 23 e 1.326 por município, em Santa Catarina.

Neste último estado, em geral, é baixo o percentual de domicílios atendidos por saneamento inadequado (variando entre $0,1 \%$ e $2,8 \%$ ), destacando-se, negativamente, apenas os municípios de Luiz Alves e Nova Trento (com 7,8\% e 10,9\%, respectivamente).

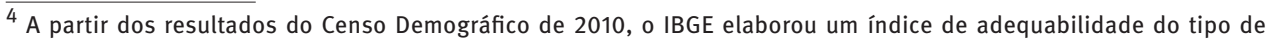
saneamento, objetivando dimensionar as condições de saneamento básico dos domicílios, sendo então considerado "adequado" o domicílio com escoadouro ligado à rede geral ou à fossa séptica, servido de água proveniente de rede geral de abastecimento e com destino do lixo coletado direta ou indiretamente pelos serviços de limpeza; "semiadequado" aquele que possuía, pelo menos, um dos serviços de abastecimento de água, esgoto ou lixo classificado como adequado; e "inadequado" aquele que não apresentou qualquer condição de saneamento básico considerado adequado (IBGE, 2011).
} 
Em Luiz Alves, apenas 9,5\% dos domicílios tinham saneamento adequado em 2010 e, em Nova Trento, apenas $10,9 \%$ de domicílios.

\section{TABELA 1}

População residente, domicílios particulares permanentes e tipo de saneamento básico, por condição urbana e rural

Municípios selecionados dos Estados de Santa Catarina e Pernambuco - 2010

\begin{tabular}{|c|c|c|c|c|c|c|c|c|}
\hline \multirow{3}{*}{ Municípios } & \multirow{2}{*}{\multicolumn{2}{|c|}{$\begin{array}{l}\text { População } \\
\text { residente }\end{array}$}} & \multicolumn{6}{|c|}{ Domicílios particulares permanentes } \\
\hline & & & \multicolumn{3}{|c|}{ Número de domicílios } & \multicolumn{3}{|c|}{ Tipo de saneamento (\% de domicílios) } \\
\hline & Rural & Urbana & Rural & Urbano & Total & Inadequado & Semiadequado & Adequado \\
\hline \multicolumn{9}{|c|}{ Santa Catarina } \\
\hline Benedito Novo & 4.532 & 5.804 & 1.364 & 1.810 & 3.174 & 2,8 & 65,8 & 31,4 \\
\hline Blumenau & 14.238 & 294.773 & 4.216 & 96.871 & 101.087 & 0,1 & 13,3 & 86,7 \\
\hline Brusque & 3.478 & 102.025 & 1.042 & 32.195 & 33.237 & 0,3 & 19,9 & 79,8 \\
\hline Camboriú & 3.130 & 59.231 & 1.050 & 17.251 & 18.301 & 0,1 & 19,4 & 80,5 \\
\hline Gaspar & 10.855 & 47.126 & 3.396 & 14.565 & 17.961 & 0,3 & 22,9 & 76,8 \\
\hline Ilhota & 4.457 & 7.898 & 1.373 & 2.449 & 3.822 & 2,2 & 61,4 & 36,4 \\
\hline Itajaí & 9.921 & 173.452 & 3.028 & 54.725 & 57.753 & 0,1 & 14,2 & 85,7 \\
\hline Itapoá & 591 & 14.172 & 195 & 4.827 & 5.022 & 0,4 & 19,9 & 79,7 \\
\hline Luiz Alves & 7.182 & 3.256 & 2.106 & 966 & 3.072 & 7,8 & 82,7 & 9,5 \\
\hline Nova Trento & 3.061 & 9.129 & 933 & 2.898 & 3.831 & 10,9 & 38,8 & 50,3 \\
\hline Pomerode & 3.936 & 23.823 & 1.138 & 7.422 & 8.560 & 0,6 & 26,5 & 72,9 \\
\hline Rio dos Cedros & 5.174 & 5.110 & 1.594 & 1.633 & 3.227 & 1,1 & 59,0 & 39,9 \\
\hline Timbó & 2.478 & 34.296 & 718 & 10.930 & 11.648 & 0,3 & 46,6 & 53,1 \\
\hline \multicolumn{9}{|l|}{ Pernambuco } \\
\hline Água Preta & 14.345 & 18.750 & 3.140 & 4.590 & 7.730 & 31,9 & 34,1 & 34,0 \\
\hline Barreiros & 6.750 & 33.982 & 1.623 & 8.817 & 10.440 & 18,5 & 42,9 & 38,6 \\
\hline Catende & 8.959 & 28.861 & 2.101 & 7.874 & 9.975 & 15,4 & 26,4 & 58,3 \\
\hline Correntes & 7.090 & 10.329 & 1.776 & 2.572 & 4.348 & 27,5 & 35,1 & 37,4 \\
\hline Cortês & 4.551 & 7.901 & 1.177 & 2.147 & 3.324 & 18,7 & 30,3 & 51,1 \\
\hline Jaqueira & 4.419 & 7.082 & 1.025 & 1.902 & 2.927 & 30,1 & 48,9 & 21,1 \\
\hline Maraial & 3.671 & 8.559 & 897 & 2.170 & 3.067 & 23,0 & 59,2 & 17,8 \\
\hline Palmares & 12.640 & 46.886 & 3.102 & 12.294 & 15.396 & 14,6 & 30,5 & 54,8 \\
\hline Primavera & 4.860 & 8.579 & 1.295 & 2.379 & 3.674 & 21,2 & 46,5 & 32,3 \\
\hline $\begin{array}{l}\text { São Benedito } \\
\text { do Sul }\end{array}$ & 6.783 & 7.158 & 1.400 & 1.777 & 3.177 & 36,5 & 45,1 & 18,4 \\
\hline $\begin{array}{l}\text { Vitória de } \\
\text { Santo Antão }\end{array}$ & 16.545 & 113.429 & 4.620 & 34.826 & 39.446 & 8,6 & 35,3 & 56,2 \\
\hline
\end{tabular}

Fonte: IBGE. Cidades: Informações sobre os municípios brasileiros (http://ibge.gov.br/cidadesat/xtras/home.php).

Nota: Municípios que foram decretados em situação de calamidade pública após as enchentes de 2008 em Santa Catarina e 2010 em Pernambuco.

Em Pernambuco, entre os 12 municípios analisados, apenas cinco possuíam mais da metade de seus domicílios particulares permanentes atendidos por saneamento ambiental adequado. 0 saneamento, portanto, pode ser considerado um ponto crítico nas análises dos municípios de Pernambuco. Por exemplo, em Maraial, apenas 17,8\% de domicílios tinham saneamento adequado (IBGE, 2010).

$O$ estado nutricional também é uma característica divergente entre os dois estados. De acordo com dados do Sisvan (BRASIL, 2015b), o número de usuários da atenção básica de 
saúde acompanhados com relação ao estado nutricional chegou a 2.946 no município de Barreiros/PE em 2007. Já em Santa Catarina, o maior número de pessoas acompanhadas no mesmo ano foi de 533 em Luiz Alves (Tabela 2).

TABELA 2

Número de usuários da atenção básica de saúde com acompanhamento nutricional, segundo faixas etárias Municípios selecionados dos Estados de Pernambuco e Santa Catarina - 2010

\begin{tabular}{|c|c|c|c|c|c|c|c|c|}
\hline \multirow[b]{2}{*}{ Faixas etárias } & \multicolumn{4}{|c|}{ Pernambuco } & \multicolumn{4}{|c|}{ Santa Catarina } \\
\hline & Barreiros & Catende & Palmares & $\begin{array}{c}\text { Vitória } \\
\text { de Santo } \\
\text { Antão }\end{array}$ & Blumenau & $\begin{array}{l}\text { Luiz } \\
\text { Alves }\end{array}$ & Pomerode & $\begin{array}{l}\text { Rio dos } \\
\text { Cedros }\end{array}$ \\
\hline Menos de 5 anos & 1.309 & 332 & 42 & 67 & 206 & 328 & 201 & 51 \\
\hline De 5 a 9 anos & 1.594 & 589 & 152 & 68 & 299 & 34 & 90 & 39 \\
\hline De 10 a 19 anos & 4 & 597 & 526 & - & - & 43 & 17 & - \\
\hline De 20 a 60 anos & 39 & 914 & 1325 & 3 & 1 & 128 & 52 & - \\
\hline 60 anos e mais & - & 234 & 126 & - & - & - & - & - \\
\hline Total & 2.946 & 2.666 & 2.171 & 138 & 506 & 533 & 360 & 90 \\
\hline
\end{tabular}

Fonte: Ministério da Saúde. Registro de informações do estado nutricional das famílias no Sisvan - módulo de gestão municipal (BRASIL, 2015b).

Outra variável importante para caracterizar a população com relação aos impactos em saúde é a cobertura de imunização, ressaltando que, neste caso, o que se procura verificar é a porcentagem de pessoas já imunizadas antes da ocorrência do desastre, principalmente a vacina dupla adulto, contra difteria e tétano. Considerando-se que a imunização pós-impacto não é indicada, pois não haveria tempo suficiente para efetivação da vacina e poderia haver um entendimento equivocado de proteção, com maior exposição da população a riscos de contaminação, ganham importância nos estudos os dados sobre a imunização prévia.

Nos dois estados os valores de cobertura de imunização tiveram um grande aumento entre 1994 e 2014. Em 2009, ano anterior ao desastre de Pernambuco, a média de cobertura entre os municípios analisados foi de $94 \%$, sendo o valor mínimo (66\%) registrado para o município de Água Preta e o máximo (94\%) para o de Cortês (BRASIL, 2015a). Para Santa Catarina, os valores do ano anterior (2007) variaram entre $68 \%$ para Pomerode e $89 \%$ para Luiz Alves, sendo a média de cobertura de $89 \%$ entre os municípios analisados (BRASIL, 2015a). Os valores de cobertura de imunização são coerentes com os baixos números registrados no mesmo portal para as doenças para as quais existem vacinas disponíveis nos serviços públicos de saúde.

Para caracterizar a quinta variável indicada por Watson, Gayer e Connolly (2007) - grau de acesso a serviços de saúde e gerenciamento efetivo de casos -, usamos como aproximação os dados disponibilizados pelo IBGE (2010) para o ano de 2009. Em virtude de o desastre em Santa Catarina ter ocorrido em ano anterior aos dados (2008), as informações apresentadas podem estar superestimadas, mas, ainda assim, demonstram a situação problemática para os municípios de Gaspar, Ilhota, Itapoá, Rio dos Cedros e Rodeio, que não dispunham de leitos em seus estabelecimentos de saúde (Gráfico 1), indicando a necessidade de transportar a população para municípios vizinhos. Em uma situação de 
desastre, em que as vias de transporte podem ficar obstruídas, este é um fator importante na determinação da vulnerabilidade dos municípios.

\section{GRÁFICO 1}

Estabelecimentos de saúde públicos e privados e quantidade de leitos Municípios selecionados dos Estados de Santa Catarina e Pernambuco -2009
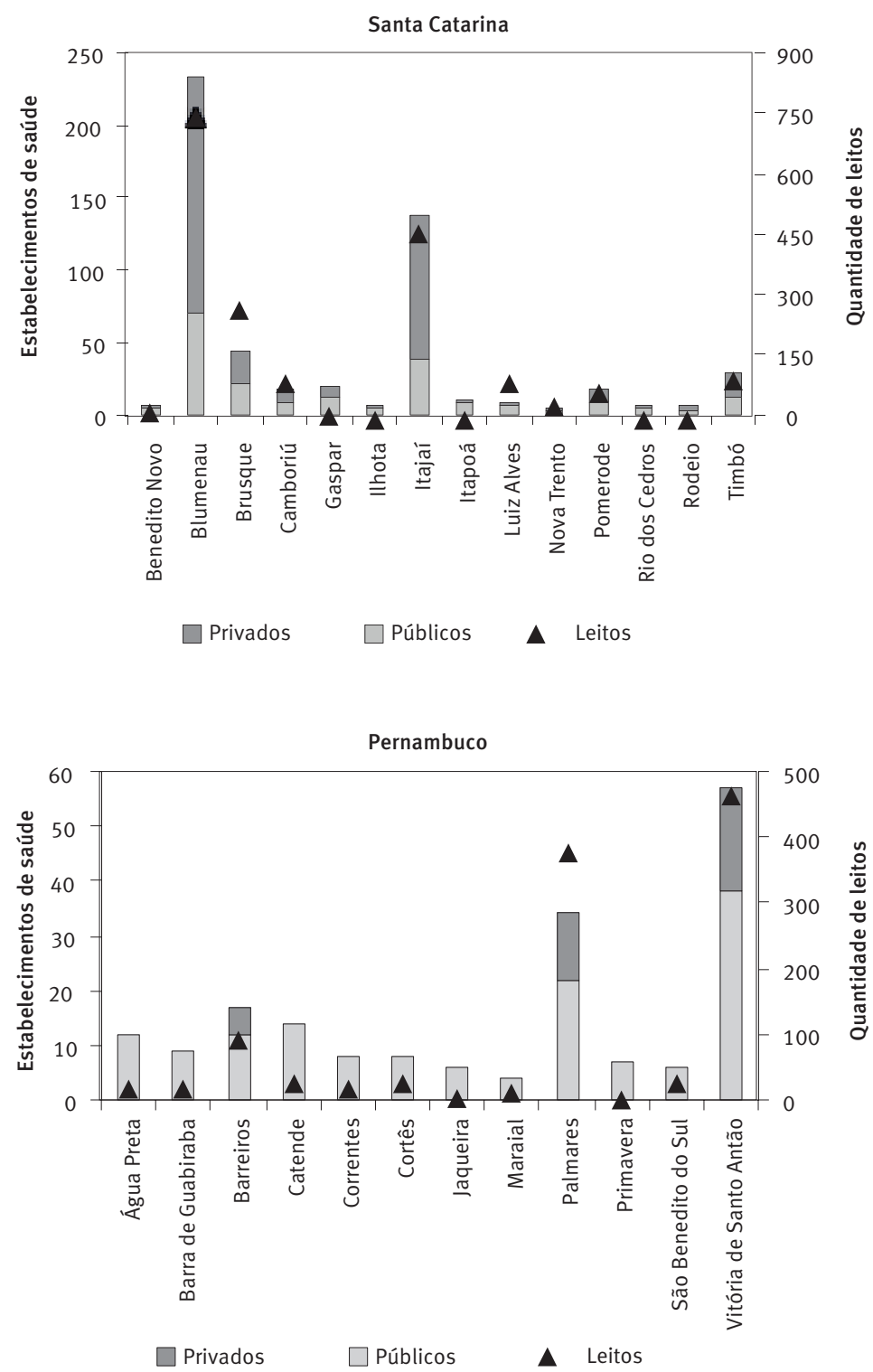

Fonte: IBGE. Cidades: Serviços de Saúde (http://ibge.gov.br/cidadesat/xtras/home.php). 
Para os municípios analisados em Pernambuco, apenas Primavera não dispunha de leitos ambulatoriais ou hospitalares em 2009. Dos 12 municípios de Pernambuco, apenas Barreiros, Palmares e Vitória de Santo Antão contavam com estabelecimentos privados de saúde (Gráfico 1). Em Santa Catarina, todos os municípios analisados possuíam estabelecimentos privados de saúde, sendo que em Blumenau e Itajaí existiam mais estabelecimentos privados do que públicos.

\section{Impactos dos desastres na saúde pública}

\section{Danos materiais da estrutura de atendimento}

Nas inundações de 2008 em Santa Catarina, em 14 municípios foi decretado estado de calamidade pública e, em 59, situação de emergência. ${ }^{5}$ Nas inundações ocorridas em Pernambuco em 2010, 67 municípios foram afetados, entre os quais 29 decretaram situação de emergência e 12 estado de calamidade pública (BANCO MUNDIAL, 2012; BRASIL, 2010b).

Os danos associados à estrutura de atendimento referem-se à destruição e/ou danificação de infraestruturas como estações de tratamento de água, postos de saúde e hospitais, bem como de equipamentos e estoque de remédios.

A quantidade de hospitais e centros de saúde danificados ou destruídos em desastres chama a atenção não apenas no Brasil, mas em toda a América Latina e Caribe. No Peru, após chuvas intensas em 1997 e 1999, foram registrados 437 hospitais e centros de saúde danificados e/ou destruídos. Em El Salvador, foram 79 atingidos após os intensos terremotos registrados em janeiro e fevereiro de 2001 (OPAS, 2003). No Brasil, os impactos de desastres no setor de saúde também têm sido expressivos, e talvez falte engajamento em campanhas como "Hospitais seguros frente a desastres". ${ }^{6}$

Os custos com perdas e danos decorrentes das inundações em Santa Catarina, em 2008 , somaram $\mathrm{R} \$ 4,75$ bilhões, distribuídos nos setores de infraestrutura (transportes, água e saneamento), social (habitação, saúde e educação) e produtivo (agricultura, indústria e comércio).

O Estado de Santa Catarina conta com alta proporção de hospitais privados em relação aos públicos (Gráfico 1). Os custos com as perdas e danos calculados no setor de saúde somaram R\$ 155 milhões, o que representa cerca de 3,7\% do impacto total do desastre, e concentraram-se no setor público (99\%) (BANCO MUNDIAL, 2012). Os danos estão associados à destruição ou danificação das infraestruturas de apoio ao setor (hospitais, postos de saúde e equipamentos) e contabilizaram R \$100 milhões, o que corresponde a $65 \%$ dos custos totais do desastre para o setor de saúde. Os prejuízos se concentram nos impactos diretos em unidades de saúde (R\$ 96 milhões) e custos de recuperação de hospitais

\footnotetext{
${ }^{5}$ Situação de emergência é o "reconhecimento (legal) pelo poder público de situação anormal, provocada por desastres, causando danos superáveis (suportáveis) pela comunidade afetada” (BRASIL, 2007a, p. 8).

${ }^{6}$ Promovida, em 2008, pela Estratégia Internacional de Redução de Desastres e Organização Mundial de Saúde.
} 
(R\$3,4 milhões). Em termos absolutos, as chuvas afetaram 129 unidades de saúde públicas e 48 privadas (BANCO MUNDIAL, 2012).

Em Ilhota, dos quatro estabelecimentos públicos de saúde existentes, dois foram danificados e dois foram destruídos. Em Blumenau, $60 \%$ dos estabelecimentos públicos foram danificados (38) ou destruídos (quatro). Em Itajaí, 52\% foram danificados (20) (Figura 2). Destaca-se que nestes municípios houve uma grande porcentagem de afetados nos desastres e que possivelmente demandaram ações extras dos serviços de saúde que foram atingidos. Em Ilhota, 28\% da população (3.500 pessoas) foi afetada, em Blumenau, 33\% (103 mil pessoas) e, em Itajaí, 89\% (163.219).

Os impactos no setor de infraestrutura de água e saneamento foram responsáveis por custos totais de $\mathrm{R} \$ 29,2$ milhões. Desse total, mais da metade correspondeu a danos nos sistemas de distribuição de água, concentrando-se em estações de tratamento de água - ETA (R\$ 9 milhões) e redes de distribuição (R\$ 7 milhões), e aproximadamente $25 \%$ referiram-se a perdas na coleta e tratamento de lixo não realizados (BANCO MUNDIAL, 2012).

Em Pernambuco, os danos calculados no setor saúde somaram R\$146 milhões, o que representou cerca de $5 \%$ do impacto total do desastre e $6 \%$ dos prejuízos identificados no setor social (habitação, saúde e educação) (BANCO MUNDIAL, 2012). 0 valor de reconstrução das unidades de atendimento destruídas e danificadas de Palmares (Hospital Regional), Barreiros, Água Preta, Cortês e Jaqueira, em Pernambuco, chegaram a R\$ 91,6 milhões (BANCO MUNDIAL, 2012).

Na rede hospitalar de Pernambuco, a região da Mata Sul sofreu o maior impacto: de um total de 18 hospitais existentes, três hospitais municipais e um regional foram destruídos, o que corresponde a uma perda de $22 \%$ na rede de atendimento.

Além disso, foram destruídas 18 Unidades Básicas de Saúde, enquanto outras 18 foram danificadas pelas chuvas. 0 setor também foi afetado pela destruição do prédio de uma das gerências regionais da Secretaria de Estado da Saúde de Pernambuco.

Em Cortês/PE, 87,5\% dos estabelecimentos públicos de saúde foram danificados (quatro) ou destruídos (três). Em Barreiros, essa proporção chegou a $83 \%$, sendo nove danificados e um destruído e, em Palmares, alcançou 77\% (Figura 1). Em relação à população municipal atingida no desastre, destacam-se os municípios de Maraial e Barreiros, onde a totalidade dos habitantes (12.352 e 41.748, respectivamente) foi afetada, e Palmares com 99\% (58.819). Destaca-se que em Palmares e Barreiros houve uma grande porcentagem de afetados nos desastres e que possivelmente demandaram ações extras dos serviços de saúde que foram atingidos. 0 município de Palmares, que no período pré-impacto contava com 22 hospitais públicos e 376 leitos, teve 15 unidades danificadas e duas destruídas.

Além disso, o relatório do Banco Mundial reconhece que os valores foram subdimensionados, pois não foram calculados os custos de instalações provisórias, o valor dos atendimentos médicos não realizados pelos hospitais de pequeno porte e UBS e os impactos do deslocamento da equipe do Hospital Regional de Palmares/PE para hospitais particulares da região (BANCO MUNDIAL, 2012). Logo, as perdas indiretas 
associadas aos danos causados à infraestrutura do setor foram, de fato, maiores do que as calculadas.

Os hospitais de Barreiros, Cortes, Água Preta e Jaqueira, em Pernambuco, foram reconstruídos em 2013, em áreas não sujeitas a riscos. 0 Hospital de Palmares/PE também foi construído em uma área sem risco de enchente em 2011.

A preparação destes estabelecimentos para lidar com eventos adversos implica que sejam considerados nos planos de contingência das Defesas Civis. Pereira et al. (2014) mencionam o índice de segurança hospitalar, desenvolvido pela Organização Panamericana de Saúde (Opas), que possibilita estimar a probabilidade de um estabelecimento de saúde continuar funcionando após a ocorrência de um desastre. Ainda, é preciso planejar a construção e reconstrução de instalações de saúde. Atualmente há documentos que oferecem diretrizes para este planejamento, como o da Opas (2003) e o guia de Boroschek Krauskopf (2004). Estes documentos abordam critérios para seleção de locais, detalhes de projetos, avaliação de profissionais requeridos e procedimentos para garantir a qualidade dos projetos. Adicionalmente, a tecnologia de "construção acelerada" permite restabelecer com rapidez a rede pública de saúde atingida em um desastre (PEREIRA et al., 2014). Os "Estabelecimentos de Saúde Inteligentes" associam técnicas de redução do risco de desastres com o uso de energia com baixas emissões de carbono (PEREIRA et al., 2014). 0 conhecimento, portanto, existe e é acessível.

Pereira et al. (2014) também enfatizam a importância de ampliar a resposta pós-impacto para além do atendimento médico e hospitais seguros, gerenciando abrigos e trabalhos de vigilância sanitário-epidemiológica e evitando a disseminação de agravos de saúde.

\section{Danos sofridos pela população em curto, médio e longo prazos}

Como consequência dos desastres analisados, ocorreram 26 óbitos no município de Ilhota/SC e 24 em Blumenau/SC, chegando a um total de 89 óbitos entre os municípios catarinenses analisados, de acordo com registros de Avadan (BRASIL, 2010b). Xavier, Barcellos e Freitas (2014) encontraram discrepâncias entre o número de óbitos contabilizado pela Defesa Civil, pelo Sistema de informação de mortalidade (SIM) do SUS e pela imprensa, com exceção para Blumenau e Jaraguá do Sul, com respectivamente 24 e 13 óbitos de acordo com as três fontes de informação.

No Estado de Pernambuco foram registrados oito óbitos decorrentes das inundações de 2010. Considerando números absolutos de feridos e enfermos, o município mais afetado de Pernambuco foi Palmares (6.090). Em Santa Catarina, os números de enfermos também são expressivos, principalmente em Blumenau (2.863), Itajaí (2.088), Gaspar (281) e Pomerode (157).

De acordo com Carmo e Anazawa (2014), a composição etária da população pode influenciar na vulnerabilidade aos desastres. Nos estados em estudo, a faixa etária de 15 a 64 anos foi a mais impactada, tanto em número de mortes (38 em SC e seis em PE) quanto de feridos e enfermos (4.159 e 5.631, respectivamente) (Tabela 3). 
TABELA 3

Número de mortos, feridos e enfermos em inundações, por grupos etários Municípios selecionados de Santa Catarina (2008) e Pernambuco (2010)

\begin{tabular}{|c|c|c|c|c|c|c|c|c|c|c|}
\hline \multirow[b]{2}{*}{ Municípios } & \multicolumn{5}{|c|}{ Mortes } & \multicolumn{5}{|c|}{ Feridos e enfermos } \\
\hline & $\begin{array}{c}0-14 \\
\text { anos }\end{array}$ & $\begin{array}{l}15-64 \\
\text { anos }\end{array}$ & $\begin{array}{c}65 \\
\text { anos e } \\
\text { mais }\end{array}$ & Gestantes & Total & $\begin{array}{c}0-14 \\
\text { anos }\end{array}$ & $\begin{array}{c}15-64 \\
\text { anos }\end{array}$ & $\begin{array}{l}65 \text { anos } \\
\text { e mais }\end{array}$ & Gestantes & Total \\
\hline Santa Catarina & 18 & 38 & 8 & 1 & 89 & 1.064 & 4.159 & 383 & 24 & 5.630 \\
\hline Benedito Novo & 0 & 1 & 1 & 0 & $\begin{array}{r}2 \\
(0,02 \%)\end{array}$ & 0 & 2 & 1 & 0 & $\begin{array}{r}3 \\
(0,03 \%)\end{array}$ \\
\hline Blumenau & $\ldots$ & $\ldots$ & $\ldots$ & $\cdots$ & $\begin{array}{r}24(1) \\
(0,01 \%)\end{array}$ & 241 & 2.424 & $\begin{array}{r}24 \\
(0,01 \%)\end{array}$ & 11 & $\begin{array}{r}2.863 \\
(0,97 \%)\end{array}$ \\
\hline Brusque & 0 & 1 & 0 & 0 & 1 & 21 & 20 & 24 & 1 & $\begin{array}{r}66 \\
(0,06 \%)\end{array}$ \\
\hline Camboriú & 0 & 0 & 0 & 0 & 0 & 0 & 0 & 0 & 0 & 0 \\
\hline Gaspar & 5 & 8 & 2 & 1 & $\begin{array}{r}16 \\
(0,03 \%)\end{array}$ & 56 & 178 & 41 & 6 & $\begin{array}{r}281 \\
(0,48 \%)\end{array}$ \\
\hline Ilhota & 7 & 18 & 1 & 0 & $\begin{array}{r}26 \\
(0,21 \%)\end{array}$ & 19 & 63 & 20 & 6 & $\begin{array}{r}108 \\
(0,87 \%)\end{array}$ \\
\hline Itajaí & 2 & 3 & 0 & 0 & $\begin{array}{r}5 \\
(0,0 \%)\end{array}$ & 702 & 1.302 & 84 & 0 & $\begin{array}{r}2.088 \\
(1,14 \%)\end{array}$ \\
\hline Itapoá & 0 & 0 & 0 & 0 & 0 & 3 & 0 & 0 & 0 & $\begin{array}{r}3 \\
(0,02 \%)\end{array}$ \\
\hline Luiz Alves & 4 & 3 & 3 & 0 & $\begin{array}{r}10 \\
(0,10 \%)\end{array}$ & 12 & 42 & 7 & 0 & $\begin{array}{r}61 \\
(0,58 \%)\end{array}$ \\
\hline Nova Trento & 0 & 0 & 0 & 0 & 0 & 0 & 0 & 0 & 0 & 0 \\
\hline Pomerode & 0 & 2 & 1 & 0 & $\begin{array}{r}3 \\
(0,01 \%)\end{array}$ & 10 & 128 & 19 & 0 & $\begin{array}{r}157 \\
(0,57 \%)\end{array}$ \\
\hline Rio dos Cedros & 0 & 0 & 0 & 0 & 0 & 0 & 0 & 0 & 0 & 0 \\
\hline Timbó & 0 & 2 & 0 & 0 & $\begin{array}{r}2 \\
(0,01 \%) \\
\end{array}$ & 0 & 0 & 0 & 0 & 0 \\
\hline Pernambuco & 0 & 6 & 2 & 0 & 8 & 49 & 5.631 & 583 & 4 & 6.267 \\
\hline Água Preta & 0 & 2 & 0 & 0 & $\begin{array}{r}2 \\
(0,01 \%)^{2}\end{array}$ & 29 & 52 & 7 & 3 & $\begin{array}{r}91 \\
(0,28 \%)\end{array}$ \\
\hline Barreiros & 0 & 2 & 0 & 0 & $(0,00 \%)$ & 0 & 0 & 0 & 0 & 0 \\
\hline Catende & 0 & 0 & 1 & 0 & $\begin{array}{r}1 \\
(0,00 \%)\end{array}$ & 5 & 25 & 6 & 0 & $\begin{array}{r}36 \\
(0,10 \%)\end{array}$ \\
\hline Correntes & 0 & 0 & 0 & 0 & 0 & 0 & 0 & 0 & 0 & 0 \\
\hline Cortês & 0 & 1 & 0 & 0 & $\begin{array}{r}1 \\
(0,01 \%)\end{array}$ & 6 & 15 & 2 & 1 & $\begin{array}{r}24 \\
(0,19 \%)\end{array}$ \\
\hline Jaqueira & 0 & 0 & 0 & 0 & 0 & 0 & 0 & 0 & 0 & 0 \\
\hline Maraial & 0 & 0 & 1 & 0 & $\begin{array}{r}1 \\
(0,01 \%)\end{array}$ & 8 & 2 & 6 & 0 & $\begin{array}{r}16 \\
(0,13 \%)\end{array}$ \\
\hline Palmares & 0 & 0 & 0 & 0 & 0 & 0 & 5.531 & 559 & 0 & $\begin{array}{r}6.090 \\
(10,23 \%)\end{array}$ \\
\hline Primavera & 0 & 0 & 0 & 0 & 0 & 0 & 0 & 0 & 0 & 0 \\
\hline $\begin{array}{l}\text { São Benedito } \\
\text { do Sul }\end{array}$ & 0 & 0 & 0 & 0 & 0 & 0 & 0 & 0 & 0 & 0 \\
\hline $\begin{array}{l}\text { Vitória de Santo } \\
\text { Antão }\end{array}$ & 0 & 1 & 0 & 0 & $\begin{array}{r}1 \\
(0,00 \%) \\
\end{array}$ & 1 & 6 & 3 & 0 & $\begin{array}{r}10 \\
(0,01 \%) \\
\end{array}$ \\
\hline
\end{tabular}

Fonte: Ministério da Integração Social - Avadan.

(1) Não foi informada, no Avadan, a desagregação por grupo etário para Blumenau. 
Em números relativos, chama atenção a situação do município de Palmares/PE, onde $10 \%$ da população encontrava-se no grupo de enfermos e feridos, sendo a maior parte também na faixa entre 15 e 64 anos. Quatro gestantes estiveram entre os enfermos/feridos de Pernambuco e 24 em Santa Catarina. Uma gestante faleceu em Gaspar/SC.

O número de mortos e feridos, entretanto, deve ser analisado com critérios. Carmo e Anazawa (2014), em análise geral das bases de dados de desastres ocorridos no Brasil, mostram que não é possível afirmar se os desastres e a mortalidade por desastres estão aumentando no país devido às variações dos eventos. Além disso, de acordo com os autores, pode haver classificações equivocadas das causas de mortes e existe a possibilidade de o desastre não ser a causa básica nos registros obituários. Xavier et al. (2014) também destacam a inconsistência no registro dos dados e afirmam que nem sempre há coincidência entre os locais atingidos pelos desastres e as áreas com maior número de feridos e mortos, devido à concentração dos impactos em áreas de maior densidade demográfica e consideradas mais vulneráveis.

Segundo Alves (2006), para os municípios de Santa Catarina, não se verifica sobreposição de vulnerabilidade ambiental e vulnerabilidade social em escala municipal. Blumenau e Itajaí, por exemplo, não apresentam vulnerabilidade social em escala municipal, entretanto, tiveram altos números de mortos e afetados em decorrência do desastre (Tabela 3). Acreditamos que, nestes casos, a vulnerabilidade ambiental seja determinante, pois as características de ocupação dos municípios da Bacia do Itajaí colocam grande parte da população em situação de risco, apesar de seus melhores indicadores socioeconômicos. 0 relevo acidentado, com vales encaixados e encostas íngremes, condicionou a ocupação humana nas planícies fluviais - áreas naturalmente sujeitas a inundações - e encostas, áreas sujeitas a movimentos de massa. Somam-se a isso os processos de industrialização e desenvolvimento econômico que atraíram fluxos migratórios e induziram ocupações e intervenções no ambiente - como desmatamentos, cortes, aterros e construções precárias.

Os impactos em curto prazo de desastres também incluem aumento do número de ocorrências de patologia crônica, como hipertensos, diabéticos e cardiopatas, cujos quadros tornam-se mais agudos pela falta de medicamentos. Em médio prazo, podem ser incluídas as doenças transmitidas por vetores, como dengue e malária, e também aquelas relacionadas à exposição à água contaminada, como a leptospirose.

Xavier, Barcellos e Freitas (2014) mostram aumento no número de internações por leptospirose, doenças infecciosas, fraturas e acidente vascular cerebral em 2008 , quando comparadas às médias de 2007 e 2009 (respectivamente anterior e posterior ao desastre), nos municípios de Itajaí, Blumenau e Ilhota. Ressalta-se também o prolongamento destes efeitos até seis meses após o evento, fato que normalmente não é registrado nos dados de enfermos realizados pela Defesa Civil.

De acordo com Alves e Torres (2006, p. 54), “o indicador que mais revela e explicita a associação entre exposição a risco ambiental e má qualidade do ambiente doméstico é a presença de insetos e roedores", sendo também comum a existência de insetos e baratas. 
Esta associação é evidenciada nos impactos à saúde em situações de desastres, especialmente nas relações entre inundações e casos de leptospirose, que é uma zoonose causada por uma bactéria do gênero Leptospira, presente na urina de ratos. Após inundações, esta bactéria, quando dispersa no ambiente, pode misturar-se com as águas e provocar o contágio da população em contato com essa água contaminada.

Em 2008, em Santa Catarina, foram notificados 1.900 casos suspeitos da doença, em sua maior parte registrados nos municípios atingidos pelas inundações na região do vale do Rio Itajaí, ocorridas em novembro (SANTOS et al., 2012). Nos locais estudados neste trabalho, Blumenau e Itajaí tiveram aumento de aproximadamente quatro vezes no número de casos de leptospirose após as inundações de novembro de 2008 (Tabela 4). Alguns municípios de Pernambuco também registraram crescimento no número de casos após as inundações de junho de 2010 (Tabela 5).

Guimarães et al. (2014) sugerem que há um intervalo de tempo entre o pico de precipitação e o surgimento dos sintomas, devido ao período de latência da doença. Nas Tabelas 4 e 5 também é evidenciada esta ampliação dos efeitos nos meses posteriores às inundações.

TABELA 4

Casos de leptospirose confirmados e notificados no Sistema de Informação de Agravos de Notificação - Sinan Net

Municípios do Estado de Santa Catarina - 2008

\begin{tabular}{lccccccccccrrr}
\hline \multicolumn{1}{c}{ Municípios } & Jan. & Fev. & Mar. & Abr. & Maio & Jun. & Jul. & Ago. & Set. & Out. & Nov. & Dez. & Total \\
\hline Blumenau & 5 & 3 & 2 & 2 & 1 & 0 & 0 & 1 & 0 & 1 & 21 & 126 & 162 \\
Brusque & 3 & 2 & 0 & 0 & 0 & 0 & 0 & 1 & 0 & 0 & 0 & 2 & 8 \\
Balneário Camboriú & 0 & 2 & 1 & 0 & 1 & 1 & 0 & 1 & 0 & 0 & 3 & 19 & 28 \\
Gaspar & 0 & 0 & 1 & 0 & 0 & 0 & 0 & 0 & 0 & 0 & 3 & 20 & 24 \\
Ilhota & 0 & 0 & 0 & 0 & 0 & 0 & 0 & 0 & 0 & 1 & 3 & 6 & 10 \\
Itajaí & 3 & 6 & 3 & 0 & 0 & 2 & 0 & 0 & 1 & 0 & 16 & 130 & 161 \\
Itapoá & 0 & 0 & 0 & 0 & 0 & 0 & 0 & 0 & 0 & 0 & 1 & 0 & 1 \\
Luiz Alves & 0 & 0 & 0 & 0 & 0 & 0 & 0 & 0 & 0 & 0 & 2 & 7 & 9 \\
Pomerode & 0 & 0 & 0 & 0 & 0 & 0 & 0 & 0 & 0 & 0 & 0 & 3 & 3 \\
Timbó & 3 & 2 & 0 & 0 & 0 & 0 & 1 & 0 & 0 & 0 & 5 & 6 & 17 \\
\hline
\end{tabular}

Fonte: Ministério da Saúde. Secretaria de Vigilância em Saúde. Sistema de Informação de Agravos de Notificação. Nota: Inundação ocorrida em novembro de 2008.

TABELA 5

Casos de leptospirose confirmados e notificados no Sistema de Informação de Agravos de Notificação - Sinan Net

Municípios do Estado de Pernambuco - 2010

\begin{tabular}{lcccccccccccccc}
\hline \multicolumn{1}{c}{ Municípios } & Jan. & Fev. & Mar. & Abr. & Maio & Jun. & Jul. & Ago. & Set. & Out. & Nov. & Dez. & Total \\
\hline Água Preta & 0 & 0 & 0 & 0 & 0 & 0 & 2 & 0 & 0 & 0 & 0 & 0 & 2 \\
Palmares & 0 & 0 & 0 & 0 & 0 & 2 & 9 & 1 & 0 & 0 & 0 & 0 & 12 \\
Vitória de Santo & 0 & 0 & 0 & 0 & 0 & 1 & 5 & 0 & 2 & 0 & 0 & 0 & 8 \\
Antão & 3 & 5 & 4 & 10 & 10 & 45 & 48 & 24 & 7 & 3 & 3 & 3 & 165 \\
Recife (1) & &
\end{tabular}

Fonte: Ministério da Saúde. Secretaria de Vigilância em Saúde. Sistema de Informação de Agravos de Notificação.

(1) Apesar de Recife não fazer parte da listagem de municípios com decreto de calamidade pública, pode haver o deslocamento de pessoas afetadas até a capital para diagnóstico e tratamento.

Nota: Inundação ocorrida em junho de 2010. 
Como exposto por Pereira e Barata (2014), "o custo de uma doença pode incluir tanto as despesas do sistema de saúde com o tratamento do agravo, quanto as despesas ou os prejuízos incorridos pela sociedade, como os dias de trabalho perdidos devido à doença ou os potenciais anos de vida perdidos devido ao agravo". 0 crescimento no número de doenças pós-impacto, em municípios de Pernambuco e Santa Catarina, portanto, aumenta o custo social dos desastres nestes estados. Também de acordo com Pereira e Barata (2014), quando o custo social da doença é parte do custo social do desastre, o impacto financeiro poderia ser usado como informação em estratégias de adaptação e resposta.

Há impactos que são ignorados ou menosprezados após a resposta imediata às emergências, principalmente quando o período posterior às chuvas se torna longo e os impactos associados à continuidade do desastre não adquirem visibilidade nos formulários de avaliação de danos e nos meios de comunicação. Em geral, pessoas afetadas nos desastres - incluindo os atingidos direta e indiretamente e também os socorristas e pessoal de apoio - sofrem impactos em função de sua condição psíquica. A porcentagem de pessoas que apresentam sintomas de danos psíquicos após a ocorrência de desastres estaria em torno de $20 \% .^{7}$ Entre as consequências estariam o uso abusivo de álcool, drogas ilícitas, depressão, insônia, irritabilidade e dificuldades de concentração (BRASIL, 2010a).

Os traumas que podem ser ocasionados por desastres são classificados como um tipo de transtorno do estresse pós-traumático (TEPT) ${ }^{8}$ (OMS, 2008). Os traumas seriam situações essencialmente violentas, como acidentes naturais (enchentes, incêndios, soterramentos), acidentes automobilísticos, assaltos, sequestros, estupros, entre outros. A categorização do TEPT como problema de saúde ajudou a reconhecer o sofrimento de pessoas cuja história traumática não era valorizada como fator determinante de seus padecimentos (CÂMARA FILHO; SOUGEY, 2001).

Além do TEPT, existem outros danos psicossociais vivenciados em longo prazo, no decorrer do processo de reconstrução e recuperação. Valencio, Siena e Marchezini (2011) analisaram as dimensões objetivas e simbólicas de afetação de grupos sociais em desastres em diferentes localidades. Os autores identificaram que a condição de abandonado é uma narrativa comum e pode ser caracterizada por uma desassistência social por parte do Estado, pela continuidade da vivência - às vezes por meses e anos - em condições insalubres em abrigos temporários ou acampamentos de desabrigados, pela insegurança física, social e emocional e pela descrença no poder público. No decorrer desse processo, as vulnerabilidades se tornam cumulativas e a continuidade do desastre silenciosamente vai se convertendo em uma catástrofe social que não adquire visibilidade (MARCHEZINI, 2014a, 2014b).

\footnotetext{
7 Discutido no seminário sobre Saúde Mental e Desastres realizado no V Defencil (Seminário Internacional de Defesa Civil, 2009).

8 Definido pela Classificação Internacional de Doenças e Problemas Relacionados à Saúde (também conhecida como Classificação Internacional de Doenças - CID 10), publicada pela Organização Mundial de Saúde (OMS).
} 
Em Ilhota/SC e Barreiros/PE, a continuidade do desastre pode ser caracterizada, entre outros aspectos: pelo luto social em decorrência da perda de parentes, amigos e vizinhos; pela perda da moradia e comprometimento dos papéis desempenhados no grupo doméstico; pela perda da estrutura produtiva, da execução do trabalho e a dimensão econômica e moral que o "ser trabalhador(a)" confere; pelo acúmulo de dívidas; pela ameaça de despejo nos abrigos temporários situados em escolas e outras instalações; pela curta duração e valor insuficiente do auxílio-moradia; pela reconstrução precária de vias de acesso, pontes, etc.; pela demora no processo de definição de novas áreas para reconstrução; e pela construção do conjunto habitacional em área periférica, sem infraestrutura de saneamento e desconectada de estrutura de serviços escolares, de saúde e de emprego (VALENCIO; MARCHEZINI; SIENA, 2011; MARCHEZINI, 2014a).

Os impactos sociais supracitados contribuem para acentuar a vulnerabilidade socioambiental em diferentes espaços urbanos e incrementar os cenários de riscos no âmbito da saúde pública. Outros impactos à saúde pública demandam análise científica e consistência de dados, como, por exemplo, o aumento no consumo de antidepressivos no pós-impacto.

Outra dimensão refere-se às especificidades dos grupos com maior vulnerabilidade em desastres, sobretudo crianças e idosos. No decorrer do processo de reconstrução do município de São Luiz do Paraitinga/SP, Marchezini (2014c) e Sartori (2014) destacam a intensificação do processo de adoecimento de idosos, que, além de ficarem desabrigados, perderam o desempenho de funções em espaços públicos simbólicos à realidade local, como igrejas, praças e outras instalações que foram destruídas. Segundo os moradores, muitos idosos vieram a falecer em razão do desastre, embora ninguém tenha morrido durante a inundação.

Investigando tais impactos, mas a partir do caso da população idosa atingida no desastre em Teresópolis/RJ, Viana (2015) expõe as divergências entre o meio oficial, a mídia e o idoso no contexto familiar e comunitário e relata "situações desumanizantes" em sua investigação: "o sofrimento vivido é de longa duração, indo além da crise aguda; o universo simbólico é negligenciado e desconsiderado na atuação pública; o cenário de cuidados a idosos fragilizados estão longe das pautas e olhar institucionais".

Entre os totais de feridos e enfermos nos locais analisados neste trabalho, 383 pessoas em Santa Catarina e 583 em Pernambuco tinham mais de 65 anos quando ocorreram os impactos. Os números absolutos são altos, principalmente se questionarmos quantos destes idosos receberam a devida atenção nas unidades de saúde, incluindo os serviços de terapia psicológica. Não conseguimos dados sobre o acompanhamento destas pessoas no período pós-impacto.

Com a consideração de aspectos esquecidos e às vezes escondidos nas considerações sobre saúde em situações de desastres, recuperamos a definição de saúde (OMS, 1946): é importante que as políticas públicas e ações pós-impacto tenham verdadeiramente a perspectiva de promover "um estado de completo bem-estar físico, mental e social". 


\section{Considerações finais}

Em um contexto de aumento da responsabilidade dos governos de proteger seus cidadãos diante dos riscos de desastres, é fundamental subsidiar as formulações de políticas públicas e as tomadas de decisões a partir do conhecimento científico. Neste trabalho, várias análises científicas ficaram limitadas ao acesso aos dados e à existência de notificação e detalhes registrados. Entre os dados notificados no Sisvan e Sinan (BRASIL, 2015a, 2015b), os casos de leptospirose são os mais expressivos para análise, porém, há doenças subnotificadas ou não notificadas que afetam as vítimas do pós-impacto, como a maioria das doenças de veiculação hídrica e os danos psicossociais.

Devido à dinâmica social, as situações de vulnerabilidade atualizam-se e novos cenários de riscos são criados, exigindo políticas contínuas para sua redução (OPAS, 2014). A análise dos desastres ocorridos em Santa Catarina (2008) e Pernambuco (2010) permitiu identificar e caracterizar as vulnerabilidades socioambientais e alguns dos impactos na saúde pública em curto, médio e longo prazos. Com relação à vulnerabilidade socioambiental, é clara a diferença entre os dois estados, em suas características e nas condições de resposta aos desastres: os municípios de Santa Catarina apresentam alto IDHM e baixos índices de pobreza, enquanto os de Pernambuco têm um índice de pobreza mais alto e IDHM mais baixo. Pernambuco conta, basicamente, com o atendimento público de saúde, enquanto Santa Catarina dispõe de uma ampla rede de hospitais particulares. Os impactos, porém, foram severos nos dois estados. Santa Catarina registrou mais óbitos do que Pernambuco e nos dois estados houve um número expressivo de feridos e enfermos. 0 aumento de casos de leptospirose também foi verificado em municípios dos dois estados. Apesar de Santa Catarina não apresentar genericamente um cenário de vulnerabilidade social, seus municípios estiveram vulneráveis devido às características geográficas dos locais impactados e, possivelmente às características de desigualdade intraurbana. Em Pernambuco houve menos óbitos, mas uma maior proporção de pessoas afetadas. Estes fatos corroboram a severidade dos impactos à saúde pública - atualmente classificados como desastres secundários - e a necessidade de inclusão do tema saúde em todas as etapas de redução de riscos de desastres: prevenção, mitigação, preparação, resposta e recuperação.

\section{Referências}

ACSELRAD, H. Ambientalização das lutas sociais - o caso do movimento por justiça ambiental. Estudos Avançados, v. 24, n. 68, p. 103-119, 2010.

Justiça ambiental e construção social do risco. In: XIII ENCONTRO NACIONAL DE ESTUDOS POPULACIONAIS, Ouro Preto. Anais... Ouro Preto: Abep, 2002. Disponivel em: 〈http:// www.abep.nepo.unicamp.br/docs/anais/pdf/2002/GT_MA_ST5_Acselrad_texto.pdf . Acesso em: 01 jul. 2008.

. Vulnerabilidade ambiental, processos e relações. In: II ENCONTRO NACIONAL DE PRODUTORES E USUÁRIOS DE INFORMAÇÕES SOCIAIS, ECONÔMICAS E TERRITORIAIS. Anais... Rio de Janeiro: IBGE, 2006. 
ACSELRAD, H. et al. 0 que é justiça ambiental. Rio de Janeiro: Garamond, 2008.

ALCÂNTARA, E.; FURTADO, F.; SUASSUNA, C.; BEZERRA, O. Resiliência e vulnerabilidade de cidades brasileiras: lições aprendidas com as catástrofes da região serrana do Rio de Janeiro e da Zona da Mata de Pernambuco. In: VI ENCONTRO NACIONAL DA ANPPAS, Belém, 2012. VI ENANPPAS - Encontro Nacional da ANPPAS. Belém: ANPPAS, 2012. v. 1, p. 1-22.

ALVES, H. P. F. Vulnerabilidade socioambiental na metrópole paulistana: uma análise sociodemográfica das situações de sobreposição espacial de problemas e riscos sociais e ambientais. Revista Brasileira de Estudos de População, v. 23, n. 1, p. 43-59, 2006.

ALVES, H. P. F.; TORRES, H. G. Vulnerabilidade socioambiental na cidade de São Paulo: uma análise de famílias e domicílios em situação de pobreza e risco ambiental. São Paulo em Perspectiva, v. 20, n. 1, p. 44-60, 2006. Disponível em: 〈http://produtos.seade.gov.br/produtos/spp/v20n01/ v20n01_04.pdf >. Acesso em: 01 jul. 2008.

BANCO MUNDIAL. Avaliação de perdas e danos: inundações e deslizamentos na Região Serrana do Rio de janeiro - Janeiro de 2011. Relatório elaborado pelo Banco Mundial com apoio do Governo do Estado do Rio de Janeiro. Brasília, novembro de 2012.

BARCELLOS, C. et al. Inter-relacionamento de dados ambientais e de saúde: análise de risco à saúde aplicada ao abastecimento de água no Rio de Janeiro utilizando Sistemas de Informações Geográficas. Cadernos de Saúde Pública, v. 3, n. 14, p. 597-605, 1998.

BOROSCHEK KRAUSKOPF, R. Guía para la reducción de la vulnerabilidad en el diseño de nuevos establecimientos de salud. Washington D.C.: OPS/Banco Mundial, 2004.

BRASIL. Ministério da Integração Nacional. Secretaria Nacional de Defesa Civil. Manual para a decretação de situação de emergência ou estado de calamidade pública. Brasília: Sedec, 2007a. v. 1.

. Ministério da Integração Nacional. Secretaria Nacional de Defesa Civil. Manual para a decretação de situação de emergência ou estado de calamidade pública. Brasília: Sedec, 2007b. v. 2

. Ministério da Integração Nacional. Secretaria Nacional de Defesa Civil. Universidade Federal de Santa Catarina. Centro Universitário de Estudos e Pesquisas sobre Desastres. Gestão de riscos e de desastres: contribuições da psicologia. Curso à distância / Centro Universitário de Estudos e Pesquisas sobre Desastres. Florianópolis: Ceped, 2010a.

. Ministério da Integração Social. Secretaria Nacional de Defesa Civil. Sistema Integrado de Informações sobre Desastres - S2ID. 2010b. Disponível em: 〈http://s2id.integracao. gov.br/relatorio/geoespacial/geoespacial.htmlı. Acesso em: maio 2015.

. Ministério da Saúde. Secretaria de Vigilância em Saúde. Sinan-net - Sistema de Informação de Agravos de Notificação. 2015a.

Ministério da Saúde. Secretaria de Vigilância em Saúde. Sistema de Vigilância Alimentar Nutricional - Sisvan. 2015b.

CÂMARA FILHO, J. W. S.; SOUGEY, E. B. Transtorno de estresse pós-traumático: formulação diagnóstica e questões sobre comorbidade. Revista Brasileira de Psiquiatria, v. 23, n. 4 , p. 221-228, 2001.

CARMO, R. L.; ANAZAWA, T. M. Mortalidade por desastres no Brasil: o que mostram os dados. Ciência e Saúde Coletiva, v. 19, n. 9, p. 3669-3681, 2014.

CPRM. Ação emergencial para reconhecimento das áreas de alto e muito alto risco a movimentos de massa e enchentes: fichas de Pernambuco. Brasília: CPRM, 2012. 
Ação emergencial para reconhecimento das áreas de alto e muito alto risco a movimentos de massa e enchentes: fichas de Santa Catarina. Brasília: CPRM, 2013.

CUTTER, S. L. Vulnerability to environmental hazards. Progress in Human Geography, v. 20, n. 4, p. 529-39, 1996.

CUTTER, S. L.; BORUFF, B. J.; SHIRLEY, W. L. Social vulnerability to environmental hazards. Social Science Quarterly, v. 84, n. 2, June 2003.

FREITAS, C. M. et al. Desastres naturais e saúde: uma análise da situação do Brasil. Ciência e Saúde Coletiva, v. 19, n. 9, p. 3645-3656, 2014.

GUIMARAES, R. M. et al . Análise temporal da relação entre leptospirose e ocorrência de inundações por chuvas no município do Rio de Janeiro, Brasil, 2007-2012. Ciência \& Saúde Coletiva, v. 19, n. 9, p. 3683-3692, set. 2014.

HERRMANN, M. L. de P. (Org.). Atlas de desastres naturais do Estado de Santa Catarina. Florianópolis: Secretaria de Estado de Segurança Pública e Defesa do Cidadão, Ceped/UFSC, 2004. Disponível em: 〈http://www.cfh.ufsc.br/ gedn/mapa.html〉. Acesso em: 15 mar. 2009.

IBGE - Instituto Brasileiro de Geografia e Estatística. Cidades: Informações sobre os municípios brasileiros. Disponível em: 〈http://ibge.gov.br/cidadesat/xtras/home.php〉. Acesso em: $13 \mathrm{de}$ jul. 2015.

Coordenação de População e Indicadores Sociais. Indicadores sociais municipais: uma análise dos resultados do universo do Censo Demográfico 2010. Rio de Janeiro: IBGE, 2011.

ISDR - International Strategy for Disaster Reduction. Global assessment report on disaster risk reduction. Geneva, Switzerland: ISDR, 2011. Disponível em: 〈http://www.unisdr.org/we/inform/ publications/19846>. Acesso em: 11 nov. 2015.

KEIPI, K.; TYSON, J. Planificación y protección financiera para sobrevivir desastres. Serie de informes técnicos del Departamento de Desarrollo Sostenible. Washington, DC.: Banco Interamericano de Desarrollo, 2002.

LAVELL, A. T. Ciencias sociales y desastres naturales en América Latina: un encuentro inconcluso. In: MASKREY, A. (Org.). Los desastres no son naturales. Panamá: La Red., 1993. p. 111-125.

MARANDOLA JR., E.; HOGAN, D. J. Vulnerabilidades e riscos: entre Geografia e Demografia. Revista Brasileira de Estudos de População, v. 22, n. 1, p. 29-53, jan./jun. 2005.

MARCHEZINI, V. Campos de desabrigados: a continuidade do desastre. São Carlos: Rima Editora, 2014a.

. La producción silenciada de los “desastres naturales” en catástrofes sociales. Revista Mexicana de Sociologia, v. 76, n. 2, p. 253-285, 2014 b.

Janeiro de 2010, São Luiz do Paraitinga/SP: lógicas de poder, discursos e práticas em torno de um desastre. Tese (Doutorado) - Programa de Pós-Graduação em Sociologia, Universidade Federal de São Carlos, São Carlos, 2014c.

OMS - Organização Mundial de Saúde. Classificação Internacional de Doenças e Problemas Relacionados à Saúde - CID10. 2008. Disponível online em: 〈http://www.cid10.com.br/contact〉. Acesso em 10 jun. 2015.

Constituição da Organização Mundial da Saúde (OMS/WHO). Nova Iorque, 1946. Disponivel em: 〈http://www.direitoshumanos.usp.br/index.php/OMS-Organiza\%C3\%A7\%C3\%A30Mundial-da-Sa\%C3\%BAde/constituicao-da-organizacao-mundial-da-saude-omswho.html`. Acesso em: 18 jun. 2015. 
OPAS - Organização Pan-Americana da Saúde. Ministério da Saúde. Desastres naturais e saúde no Brasil. Brasília, Opas, Ministério da Saúde, 2014 (Série Desenvolvimento Sustentável e Saúde, v. 2).

. Protección de las nuevas instalaciones de salud frente a desastres naturales: guía para la promoción de la mitigación de desastres. Washington, D.C.: Opas/Banco Mundial, 2003.

PEREIRA, C. A. R. et al. Avaliação econômica dos casos de dengue atribuídos ao desastre de 2011 em Nova Friburgo (RJ), Brasil. Ciência \& Saúde Coletiva, v. 19, n. 9, p. 3693-3704, set. 2014.

PEREIRA, C. A. R.; BARATA, M. M. de L. Organização dos serviços urbanos de saúde frente à mudança do clima e ao risco de desastres na América Latina. Saúde Debate, v. 38, n. 102, p. 624-634, set. 2014.

PNUD; IPEA; FJP. Atlas de desenvolvimento humano municipal brasileiro. Brasília, 2013. Disponível em: 〈http://www.atlasbrasil.org.br/2013/pt/home/〉. Acesso em: 04 nov. 2015.

SANTOS, E. V. Suscetibilidade a movimentos de massa na microbacia do Ribeirão Máximo, Município de Luis Alves, SC. Dissertação (Mestrado Profissional em Planejamento Territorial e Desenvolvimento Socioambiental) - Universidade do Estado de Santa Catarina, Florianópolis, 2012.

SANTOS, L. B. L.; ASSIS, M. C.; SILVA, A. E. P.; ANGELIS, C. F. Sobre risco, ameaça e vulnerabilidade à leptospirose em situações pós-alagamentos, inundações e enxurradas: reconstruindo o episódio do Vale do Itajaí (2008-2009). In: I CONGRESSO BRASILEIRO SOBRE DESASTRES NATURAIS. Rio Claro, 14-17 de maio de 2012. Anais... Rio Claro, 2012.

SARTORI, J. Como esquecer? Memórias de um desastre vivenciado. Dissertação (Mestrado) Escola de Engenharia, Universidade de São Paulo, São Carlos, 2014. Disponível em: 〈http:// www.teses.usp.br/teses/disponiveis/18/18139/tde-29092014-152210/pt-br.php/>. Acesso em: 18 jun. 2015.

SILVA DIAS, M. A. F. (Ed.). As chuvas de novembro de 2008 em Santa Catarina: um estudo de caso visando a melhoria do monitoramento e da previsão de eventos extremos. São José dos Campos: Inpe, 2009.

VALENCIO, N.; SIENA, M.; MARCHEZINI, V. Abandonados nos desastres: uma análise sociológica de dimensões objetivas e simbólicas de afetação de grupos sociais desabrigados e desalojados. Brasília: Conselho Federal de Psicologia, 2011.

VALENCIO, N. F. L. S. Para além do 'dia do desastre’. Curitiba: Editora Appris, 2012.

VIANA, A. S. Idoso, família e desastres: uma discussão na interface da sociologia e gerontologia a partir da análise do caso de Teresópolis/RJ. Dissertação (Mestrado) - Escola de Engenharia, Universidade de São Paulo, São Carlos, 2015. Disponível em: 〈http://www.teses.usp.br/teses/ disponiveis/18/18139/tde-09062015-154459/>. Acesso em: 17 jun. 2015.

WATSON, J. T.; GAYER, M.; CONNOLLY, M. A. Epidemics after natural disasters. Emerging Infectious Diseases, v. 13, n. 1, 2007.

XAVIER, D. R. et al. Organização, disponibilização e possibilidades de análise de dados sobre desastres de origem climática e seus impactos sobre a saúde no Brasil. Ciência \& Saúde Coletiva, v. 19, n. 9, p. 3657-3668, set. 2014.

XAVIER, D. R.; BARCELLOS, C.; FREITAS, C. M. de. Eventos climáticos extremos e consequências sobre a saúde: o desastre de 2008 em Santa Catarina segundo diferentes fontes de informação. Ambiente \& Sociedade, v. 17, n. 4, p. 273-294, dez. 2014. 


\section{Sobre os autores}

Luciana de Resende Londe é bióloga, mestre em Engenharia Agrícola pela Universidade Estadual de Campinas (Unicamp) e doutora em Sensoriamento Remoto pelo Instituto Nacional de Pesquisas Espaciais (Inpe), com especialização em Vigilância em Saúde Ambiental pela Universidade Federal do Rio de Janeiro (UFRJ). Pesquisadora em desastres naturais no Centro Nacional de Monitoramento e Alertas de Desastres Naturais (Cemaden).

Victor Marchezini é bacharel em Ciências Sociais, mestre em Sociologia pela Universidade Federal de São Carlos (UFSCar), especialista em Direitos Humanos, Gestão Global de Riscos e Políticas Públicas de Prevenção de Desastres pela Fundação Henry Dunant - América Latina e doutor em Sociologia pela Universidade Federal de São Carlos (UFScar). Pesquisador em Desastres Naturais no Centro Nacional de Monitoramento e Alertas de Desastres Naturais (Cemaden).

Rodrigo Silva da Conceição é geógrafo, mestre em Geografia e doutor em Meio Ambiente pela Universidade do Estado do Rio de Janeiro (UERJ). Tecnologista em Desastres Naturais do Centro Nacional de Monitoramento e Alertas de Desastres Naturais (Cemaden).

Katia Cristina Bortoletto é geógrafa e mestre em Ciências Florestais pela Universidade de São Paulo (USP). Tecnologista em Desastres Naturais no Centro Nacional de Monitoramento e Alertas de Desastres Naturais (Cemaden).

Ana Elisa Pereira Silva é bióloga, mestre em Sensoriamento Remoto pelo Instituto Nacional de Pesquisas Espaciais (Inpe). Analista operacional de desastres naturais no Centro Nacional de Monitoramento e Alertas de Desastres Naturais (Cemaden).

Elisa Volker dos Santos é geógrafa e mestre em Planejamento Territorial e Desenvolvimento Socioambiental pela Universidade do Estado de Santa Catarina (Udesc). Tecnologista em desastres naturais no Centro Nacional de Monitoramento e Alertas de Desastres Naturais (Cemaden).

Regina Tortorella Reani é geógrafa pela Universidade Estadual Paulista Júlio de Mesquita Filho (Unesp), mestre em Engenharia Urbana pela Universidade Federal de São Carlos (UFSCar) e doutora em Geografia pela Universidade de São Paulo (USP). Analista operacional em desastres naturais no Centro Nacional de Monitoramento e Alertas de Desastres Naturais (Cemaden).

\section{Endereço para correspondência}

Luciana de Resende Londe

Cemaden - Parque Tecnológico

Av. Doutor Altino Bondesan, 500, Distrito Eugênio de Melo

12247-016 - São José dos Campos-SP, Brasil

\section{Abstract \\ Impacts of socio-environmental disasters on public health: studies of scenarios in the Brazilian states of Santa Catarina in 2008 and Pernambuco in 2010}

Events such as floods and landslides can cause disasters that affect Brazilian public health extensively. Impacts include traumas and injuries, damage to water treatment plants and hospitals, disruption of equipment and medicine supply, epidemics and the spread of diseases, as well as lasting psychosocial damage. In this article, we study disaster scenarios in municipalities from two Brazilian states that had declared a state of public calamity as a result of flooding - Santa Catarina (2008) and Pernambuco (2010). The object was to identify and 
analyze the impacts of these disasters on social and environmental conditions as well as on the coverage of public health. To this purpose, the before and after disaster situation in affected municipalities was analyzed. To characterize socio-environmental vulnerability, we used data from the Brazilian Institute of Geography and Statistics (IBGE), the Brazilian Geological Survey (CPRM), the National Protection and Civil Defense Secretariat (SEDEC) and the Health Ministry. Although there are expressive differences between the two investigated states, especially in regards to social indicators, both of them suffered strong impacts after floods. Despite a higher human development index and low levels of poverty, Santa Catarina suffered more deaths than Pernambuco. Altogether, results demonstrate the need to include public health issues in all steps of disaster risk management.

Keywords: Vulnerability. Weather extremes. Brazil.

\section{Resumen}

Impactos de los desastres socioambientales en la salud pública: estudio de los casos de los estados brasileños de Santa Catarina en 2008 y Pernambuco en 2010

Eventos tales como las inundaciones y los derrumbes pueden causar desastres, afectando ampliamente la salud pública en Brasil. Además de las muertes, traumas y lesiones, pueden causar daños a las estaciones de tratamiento del agua, centros de salud y hospitales, comprometer el equipamiento y el stock de medicamentos, además de generar epidemias, proliferación de enfermedades y daños psicosociales. Con el objetivo de identificar y analizar las características pre y post impacto relacionadas con la salud pública, en este artículo se estudian dos escenarios: las inundaciones ocurridas en Santa Catarina en 2008 y en Pernambuco en 2010. Se analizan las condiciones socioambientales y de la cobertura de los servicios de salud previas y los daños posteriores al impacto en los municipios que decretaron el estado de emergencia pública. Para caracterizar la vulnerabilidad socioambiental se utilizaron datos del Instituto Brasileño de Geografía y Estadística (IBGE), del Servicio Geológico de Brasil (CPRM), de la Secretaría Nacional de Protección y Defensa Civil (SEDEC) y del Ministerio de Salud. Se encontraron grandes diferencias entre los dos estados, principalmente en los indicadores sociales, aunque los efectos de las inundaciones fueron severos para ambos, e incluso hubo un mayor número de muertos en Santa Catarina, estado con un alto índice de desarrollo humano y menores niveles de pobreza. Estos resultados muestran la necesidad de incluir el tema de la salud pública en todas las etapas de la gestión del riesgo de desastres.

Palabras clave: Vulnerabilidad. Fenómenos meteorológicos extremos. Brasil.

Recebido para publicação em 17/07/2015

Recomendado para publicação em 19/10/2015

Aceito para publicação em 06/11/2015 